\title{
Influential Factors of Social Entrepreneurial Intention in Bangladesh
}

\author{
Ayeasha AKHTER 1 , Md. Uzzal HOSSAIN², Ahmed Al ASHEQ ${ }^{3}$ \\ Received: June 04, 2020 Revised: June 21, 2020 Accepted: July 09, 2020
}

\begin{abstract}
The concept of social entrepreneurship (SE) is gaining attention in developing economies for the purpose of greater societal welfare maximization. Still, findings in the field of SE studies have been riddled with conflicting results and counterstatement. Also, the determinants of developing SE are not robustly investigated in developing economies like Bangladesh. This context has mobilized the authors of this current study to focus on determining student's intention to pursue SE as their career choice. Hence, the study aims to examine the predictive determinants of social entrepreneurial intentions (SEI) among Bangladeshi students. The study has investigated the influence of entrepreneurial self-efficacy, social support, prior experience, and educational support on SEI. The survey was conducted from a public university of Bangladesh, and 231 students participated in the study. Questionnaire items under each construct variable have been adopted from pre-tested research studies. Five-point Likert scale questionnaire was applied to measure the variables. SPSS version 23.0 has been used for statistical analysis through which correlation and multiple regression analysis were conducted to measure the impact of the independent variables on SEI. Results exhibited that self-efficacy, social support, and educational support positively and significantly predicted SEI, while prior experience does not influence SEI.
\end{abstract}

Keywords: Social Entrepreneurial Intention, Entrepreneurial Self-Efficacy, Social Support, Prior Experience, Educational Program

JEL Classification Code: M10, M13, J26

\section{Introduction}

Poverty, unemployment, scarcity of clean water, environmental degradation, gender discrimination, child labor, lack of education facilities, political unrest, financial inequality, hunger, insufficient medical opportunities, natural calamities are some fundamental problems faced by underdeveloped and developing countries like Bangladesh (Nowak, 2012). The underlying concept of social

${ }^{1}$ First Author. Lecturer, Department of Marketing, Faculty of Business Studies, Bangabandhu Sheikh Mujibur Rahman Science and Technology University, Bangladesh.

E-mail: ayeashasheuly@gmail.com

${ }^{2}$ Assistant Professor, Department of Management Studies, Bangabandhu Sheikh Mujibur Rahman Science and Technology University, Bangladesh. E-mail: uzzal.mgt@bsmrstu.edu.bd

${ }^{3}$ Corresponding Author. Lecturer, World School of Business, World University of Bangladesh, Bangladesh [Postal Address: Dhanmondi, Dhaka 1205, Bangladesh] E-mail: aasheq@business.wub.edu.bd

(c) Copyright: The Author(s)

This is an Open Access article distributed under the terms of the Creative Commons Attribution Non-Commercial License (http://Creativecommons.org/licenses/by-nc/4.0/) which permits unrestricted noncommercial use, distribution, and reproduction in any medium, provided the original work is properly cited. entrepreneurship (SE) for creating economic value and dealing with social issues is a tool to address problems unsolved by the government and the private sector. SE is an innovative method of creating social value while ensuring a substantial financial return. In recent times, social entrepreneurship (SE) is gaining scholarly attention, especially in the developing economies, to counteract social problems (Luc, 2018). It can be regarded as a catalyst for a society to make significant economic and social development by conquering economic, social and political disparities (Tiwari et al., 2017a). Bangladesh is considered as a leader for the concept of SE for having pioneer social enterprises like Grameen Bank and BRAC (Bornstein \& Davis, 2010). Although the genesis of social entrepreneurs has been evolving, the growth rate of social entrepreneurs is still low in Bangladesh compared with the population and social problems faced by the country. To date, very insubstantial research studies have been carried out in the context of understanding the development of SE in developing countries like Bangladesh (Rashid, 2010).

Social entrepreneurs have been incessantly contributing to bringing a substantial social change through focusing and actively working on social problems in the society of developing countries (Zeyen et al., 2012). Tiwari et al. 
(2018b) argued that, although SE is beneficial for the welfare and development of the economies, still, the present rate of social entrepreneurial growth is rather slow. This context elevates an essential query for the policymakers and scholars to understand how can the development rate of SE be enhanced and reinforced? Hence, to motivate and support social entrepreneurs, it is crucial to understand the fundamental factors that shape an individual's thinking process (Tiwari et al. 2017a). Research study stated that following the determinants of social entrepreneurial intention (SEI) is critical for academics and policymakers for encouraging individuals to become social entrepreneurs (Hockerts, 2017). Liñán and Fayolle (2015) identified that previous entrepreneurial intention studies had focused on one or more of five perspectives - theoretical aspect, individualrelated variables, entrepreneurial education, the situational factors, and intention-behavior linkage. Several scholars have signified the urgency to advance SE knowledge in the Asian region to comprehensively gauge the context of social entrepreneurial settings in local areas (Liang et al. 2017; Ip et al. 2017). This study has investigated the influential factors that are important and significant for fostering social entrepreneurial intentions (EI) among students in Bangladesh.

\section{Literature Review}

\subsection{Social Entrepreneurship}

The notion of SE is based on the concept of creating a new business venture along with realizing social benefits. SE has been defined as "a process that begins with perceived social opportunity, transfers it into an enterprise model, determines and achieves the wealth essential to execute the enterprise, initiates and grows the enterprise and yields the future upon goal achievement of the enterprise's goal" (Tiwari et al., 2017c). SE refers to "the creation of viable economic structures, relations, institutions, organizations and practices that yield ongoing social benefits" (Fowler, 2000, p. 83). Scholars have recognized that SE exhibits a dynamic process which could create value through leveraging resources in an innovative way (Shaw \& Carter, 2007). Recently, SE has been regarded as a medium to lessen socio-economic problems (Chikha \& Jarboui, 2017).

\subsection{Social Entrepreneurial Intention}

To date, many scholars have investigated the dimension of entrepreneurial intention ( $\mathrm{Lu} \&$ Wang, 2018). Entrepreneurship and entrepreneurial initiatives can only progress if entrepreneurial thinking grows and is supported (Krueger, 1993). Theory of planned behavior stated that the intention of an individual is a good determinant of a person's future course of action (Azjen, 1991). The EI is the future orientation of an individual to start a new venture and become an entrepreneur. SEI is the psychological behavior of an individual that induces a person to become a social entrepreneur by gathering knowledge, creating ideas and implementing the social business plan (Mair et al., 2006). According to Bird (1988), EI can be described as the state of mind that drives an individual to develop and establish a new business venture. Krueger and Carsrud (1993) stated that EI had been a reflection of commitment and determination towards initiating a new business venture. EI reflects an individual's personal conviction to launch and start a new business in the future (Thompson 2009). SEI can be considered as the faith and aspiration of a person to start a new social business venture (Tran \& Von Korflesch, 2016). According to Mair, et al. (2006), SEI reflects the psychological behavior of individuals which directs them to obtain innovative knowledge, novel ideas and new business plans to act as a social entrepreneur.

\subsection{Entrepreneurial Self-Efficacy}

Self-efficacy exhibits a personal appreciation of one's individual capability to accomplish a purposeful task (Bandura, 1977). Individualistic achievement is linked to one's self-efficacy. Self-efficacy is considered as individuals' belief about "their capabilities to exercise control over their level of functioning and over events that affect their lives" (Bandura, 1991; p. 275). Self-efficacy reinforces an individual's capacity to involved into initiating and completing an innovation task (Kim, 2019). The previous studies have evidenced self-efficacy as a significant predictor of social, behavioral actions, for instance, blood donation (Giles, 2004). Entrepreneurial self-efficacy (ESE) can be explained as the extent to which an individual believes that he or she can initiate a new business venture (Sánchez, 2010). ESE displays an individual's faith that he can bring some innovative solutions to the social problems within society (Hockerts, 2017). Giles et al. (2004) denoted ESE as a determinant of social behavior. Past research has found selfefficacy as a significant predictor of EI (Armitage \& Conner, 2001). Since there are many daunting social challenges, exist in society, having a substantial degree of confidence in personal capabilities is theorized as a driver of SEI (Mair \& Noboa, 2006). Mair and Noboa (2006) stated: "high level of self-efficacy allows a person to perceive the creation of a social venture as feasible, which positively affects the formation of the corresponding behavioral intention". Selfefficacy has been a salient component in the study of social entrepreneurial intention (Tiwari et al. 2017c). Hence, ESE can be regarded as a personal belief which can stimulate an individual action to solve societal problems. Thus, the following hypothesis is derived: 
Hypothesis 1: Entrepreneurial self-efficacy has a positive impact on social entrepreneurial intention.

\subsection{Social Support}

Social support (SS) reflects an individual's degree of essential support that is expected from his or her society or surroundings (Hockerts, 2017). SS can be of many forms, such as support from family, friends, government agencies, and social networks (Elali \& Al-Yacoub, 2016). For an entrepreneur, family members can facilitate a vital role in establishing a robust network and bonding with the local community that would necessarily enable an entrepreneur to involve his or herself into social activities (Anderson et al. 2005). SS is deemed critical as a medium for an individual in achieving a predetermined social outcome, followed by an entrepreneurial spirit (Hockerts, 2015). Past studies have found that family support and social network ties significantly influenced university students to pursue an entrepreneurial career (Yurtkoru et al. 2014). Previous studies have exhibited a strong and positive association between perceived social support and SEI of students (Hockerts, 2017). Hence, the following hypothesis is derived:

Hypothesis 2: Social support has a positive impact on social entrepreneurial intention.

\subsection{Prior Experience}

Prior work experience (PE) and entrepreneurial parents have been found to be a significant and influential factor of EI (Kautonen et al., 2010; Carr \& Sequeira, 2007). Past entrepreneurial experience and involvement in family business tend to influence family members' inclination for initiating entrepreneurial behavioral actions (Zhang et al., 2014). The research study demonstrated that previous experience drives pro-social attitude and activities, such as being part of a recycling initiative in society (Vining \& Ebreo, 1989). Possessing knowledge about societal problems is likely to impact SEI (Hockerts, 2017). Private entrepreneurs tend to involve in charitable poverty alleviation initiatives if they have individual past experiences in the context of inadequate educational opportunities (Yiu et al., 2014). In this study, PE is assessed to reflect an individual's prior working engagement with social organizations. Hockerts (2017) found in his research that individuals with exposure to social issues are likely to exhibit a greater degree of SEI. Hence, the following hypothesis is derived:

Hypothesis 3: Prior experience has a positive impact on social entrepreneurial intention.

\subsection{Educational Program}

Several studies have substantiated the significance of educational support as a salient predictor of EI. EI is likely to be triggered by educational programs (Vodă \& Florea, 2019). For example, the entrepreneurial educational program (EP) has been an orderly mechanism to equip students with the required level of information about entrepreneurship (Mumtaz et al., 2012). Cho (1998) advocated that EP facilitate EI since entrepreneurship-related knowledge and competence invigorate personal motivation to start a new venture. Educational institutions promote a significant role in stimulating social entrepreneurship to expand in society (Lacap et al., 2018). A study conducted by Wu and $\mathrm{Wu}(2008)$ exhibited that students, who used to be the follower of entrepreneurship education reflect a greater extent of propensity to start-up. Entrepreneurship oriented EP also transform the career choice of prospective students (Peterman \& Kennedy, 2003). It is assumed in this study that a university's educational supports via EP will stimulate students' intention to solve surrounding societal problems through beginning a new start-up. Hence, the following hypothesis is derived:

Hypothesis 4: Educational program has a positive impact on social entrepreneurial intention.

\section{Methodology}

The sample of the study was university students who were enrolled under the department of management studies. The data has been collected from the a public university of Bangladesh. All the respondents were the final semester students of Bachelor of Business Administration (BBA) program. Survey-based questionnaires were developed and distributed among the students through the class representative of each class. A total of 320 questionnaires were given to the students, and finally, 231 responses were kept for further statistical analysis, reflecting $72 \%$ feedback rate. The survey had two parts: the first part consists of necessary demographic information (i.e. age, sex), and the second part includes measurement items of variables. Likert scale was used in the current study, in which ' 1 ' represents extremely disagree and ' 5 ' represents extremely agree. A sample size of 231 can be deemed as sufficient to run multiple regression analysis (Ceresia and Mendola, 2019). For hypothesis testing purpose, the study adopted a previously tested survey questionnaire from various entrepreneurial studies.

To test the hypotheses, this study has applied the multiple regression analysis with the help of SPSS version 23, and correlation analysis has also been conducted for examining the relationship between dependent and independent variables. The item instruments of SEI, ESE, PE and SS 
have been adapted from Hockerts (2017). The items under ES variable were taken from the study by Turker and Selçuk (2009), and later questions were slightly modified according to the study needs.

The first variable was SEI, which was examined by three items (i.e., "I expect that at some point in the future I will be involved in launching an organization that aims to solve social problems"). The variable demonstrates students' intention to start a social entrepreneurial venture. The second variable was entrepreneurial ESE and was measured by three items (i.e., "I could figure out a way to help solve the problems that society faces"). The variable indicates students' extent of efficacy to solve social problems. The third variable named SS was measured by three items (i.e., "People would support me if I wanted to start an organization to help socially marginalized people"). The variable measured students' perceived support from society and the surrounding people. The fourth variable was PE and regulated by three items (i.e., "I have some experience working with social problems"). The variable examined students' extent of experience with social problems and social organizations. The fifth variable was EP and it was measured by three items (i.e. "The education in university encourages me to develop creative ideas for being a social entrepreneur").

\section{Results and Discussions}

The sample size of the present study is 231 subjects, who are full-time BBA students of a renowned public university in Bangladesh. For the research purpose, it has been confirmed that all the surveyed respondents have taken courses on entrepreneurship in their BBA program. More than half of the respondents were male students, 137 or $59 \%$, and 94 or $41 \%$ were female students. $89 \%$ of students were aged between $21-23$ years, where $11 \%$ of students' age has fallen in the category of 24-26 years of age. The age category of more than 26 years remained nil as no student reported his or her age more than 26 years. For reliability purpose, the study has applied the Cronbach's alpha coefficient $(\alpha)$ (Cronbach, 1951) method to measure the internal consistency of the items under each variable. The Cronbach's alpha $(\alpha)$ value of each variable in the study was above 0.70 (see Table 1), which is acceptable (Hair et al. 2010).

Table 2 represents the correlation analysis of this study among the dependent and independent variables. The result reveals that EP was the most influential variable that was robustly and statistically correlated with the social entrepreneurial intention $(\mathrm{r}=0.470)$, which followed by ESE $(r=0.413)$. Other two variables: SS and PE were also positively correlated with SEI.

The Durbin-Watson value of the regression model exhibited a value of 2.096, which falls under the acceptable range of 1.5 to 2.5 (Durbin \& Watson, 1951). It does imply that the regression model is a good fit for the test. The tolerance values of each variable were in between 0.1 to 1.0 , and the variance inflation factor (VIF) value was less than 5, which indicated that the model was free from the multicollinearity problem.

Table 3 presents the result of the regression analysis. The $\mathrm{R} 2$ value of 0.275 explains that the four dependent variables can explain the $27.5 \%$ variance in determining SEI. H1 states that ESE would positively impact on SEI, and the regression analysis reveals that the hypothesis is accepted $(\beta=.172, p$ $<0.05$ ). The result is consistent with past studies (Forster $\&$ Grichnik, 2013). The higher degree of self-efficacy will lead students to start social ventures in the future. H2 states that SS positively impacts SEI, and this hypothesis is also supported $(\beta=.141, \mathrm{p}<0.05)$. It does imply that social and surrounding support will stimulate students' intention for social venture creation. The finding is in line with prior studies (Hockerts, 2017). PE is hypothesized to

Table 1: Cronbach's alpha coefficient $(\alpha)$ of each variable

\begin{tabular}{|l|c|}
\hline \multicolumn{1}{|c|}{ Variables } & Cronbach $\boldsymbol{\alpha}$ \\
\hline Social entrepreneurial intention (SEI) & 0.765 \\
\hline Entrepreneurial self-efficacy (ESE) & 0.730 \\
\hline Social support (SS) & 0.746 \\
\hline Prior experience (PE) & 0.787 \\
\hline Educational Support (EP) & 0.741 \\
\hline
\end{tabular}

Table 2: Correlation Analysis

\begin{tabular}{|c|l|c|c|c|c|c|}
\hline & & $\mathbf{1}$ & $\mathbf{2}$ & $\mathbf{3}$ & $\mathbf{4}$ & $\mathbf{5}$ \\
\hline 1 & Social entrepreneurial intention (SEI) & 1 & & & \\
\hline 2 & Entrepreneurial self-efficacy (ESE) & $.413^{* *}$ & 1 & & & \\
\hline 3 & Social support (SS) & $.385^{* *}$ & $.490^{* *}$ & 1 & & \\
\hline 4 & Prior experience (PE) & $.355^{* *}$ & $.564^{* *}$ & $.518^{* *}$ & 1 & $.535^{* *}$ \\
\hline 5 & Educational Support (EP) & $.470^{* *}$ & $.513^{* *}$ & $.490^{* *}$ & 1 \\
\hline & Notes: $\mathrm{n}=231,{ }^{*} \mathrm{p}<0.05 ;{ }^{* *} \mathrm{p}<0.01$ & & & & \\
\hline
\end{tabular}


Table 3: Regression Analysis

\begin{tabular}{|l|c|c|c|c|}
\hline \multicolumn{1}{|c|}{ Variable } & R2 Change & Standardized coefficients & t & sig. \\
\hline & .275 & & & \\
\hline Entrepreneurial Self-efficacy (ESE) & & .179 & $2.432^{*}$ & .016 \\
\hline Social Support (SS) & & .141 & $1.985^{*}$ & .048 \\
\hline Prior Experience (PE) & & .023 & .301 & .764 \\
\hline Educational program (EP) & & .297 & $4.107^{* *}$ & .000 \\
\hline$\left(\mathrm{n}=231,{ }^{*} \mathrm{p}<0.05 ;{ }^{* *} \mathrm{p}<0.01\right)$ & & \\
\hline
\end{tabular}

affect SEI $(\mathrm{H} 3)$, and the hypothesis is not supported $(\beta=$ $.023, \mathrm{p}>0.05)$. The reason for this insignificant result is that the students might have experienced the failure of social organization, which would demotivate them to start their career as a social entrepreneur. The fourth hypothesis predicted that an EP would affect SEI, and the explanation is accepted $(\beta=.297, \mathrm{p}<0.01)$. The result is consistent with past studies (Souitaris et al., 2007). The finding suggests that the university's educational program and support will trigger students' intention to start social entrepreneurial activities.

\section{Conclusions}

The objective of the study was to examine the influence of ESE, EP, PE and SS on SEI of students in Bangladesh context, where social entrepreneurial studies are still moving at a slow pace. This study has found that entrepreneurial ESE, EP, and SS are crucial to induce students to become social entrepreneurs. The findings of the current study would help academics and scholars to recognize the predictors of SEI of the students who might in the future start their career as an entrepreneurial social leader to solve social problems. Our results have potential implications for entrepreneurship educators in designing academic curriculum and practical project to empower students for a social entrepreneurial career. As our students are our future for society, they are required to motivate them to be aware of social problems. The findings of the current research can be beneficial for universities to recommend social entrepreneurial courses in Bangladesh. Advancing a platform for students to start a social entrepreneurial career and deal with social problems can purposefully be sustainable in encouraging SE.

Academics and policymakers should include SE educational materials, bring successful social entrepreneurs in the class, develop the skills and confidence, provide opportunities to experience voluntary activities, and ensure external supports that are needed to be a social entrepreneur. This study has examined the four determinant factors rather than a comprehensive model of intention process that induce an individual to become a social entrepreneur. Future studies may include all aspects of the intention formation process. This study has assumed that behaviors are planned and intention to create a business lead to future action. Our assumption may be wrong in some cases as entrepreneurship can be unconscious and unplanned behavior. This study has focused on only two individual characteristics and one situation factor. Still, there are other variables like proactivity, risk-taking behavior, the moral obligation, and the environment of doing business that also may affect SEI. The study also has used the commercial, entrepreneurial intention-based model to social entrepreneurship perspective in Bangladesh.

\section{References}

Aguilar, S. J., \& Kim, A. Y. (2019). Hispanic Students' Sense of Control in Relation to Post-Secondary Enrollment Outcomes. Social Sciences, 8(2), 67. https://doi.org/10.3390/ socsci8020067

Anderson, A. R., Jack, S. L., \& Dodd, S. D. (2005). The role of family members in entrepreneurial networks: Beyond the boundaries of the family firm. Family Business Review, 18(2), 135-154. https://doi.org/10.1111/j.1741-6248.2005.00037.x

Armitage, C.J., \& Conner, M. (2001). Efficacy of the theory of planned behaviour: A meta-analytic review. British Journal of Social Psychology, 40(4), 471-499.

Ajzen, I. (1991). The theory of planned behaviour. Organizational Behaviour and Human Decision Processes, 50, 179-211.

Bandura, A. (1977). Self-efficacy: toward a unifying theory of behavioral change. Psychological Review, 84(2), 191-215. https://doi.org/10.1037/0033-295X.84.2.191

Bandura, A. (1991). Social cognitive theory of selfregulation. Organizational Behavior and Human Decision Processes, 50(2), 248-287.

Bird, B. (1988). Implementing entrepreneurial ideas: The case for intention. Academy of Management Review, 13(3), 442-453.

Bornstein, D. \& Davis, S. (2010). Social Entrepreneurship: What Everyone Needs to Know. Oxford, UK: Oxford University Press.

Carr, J.C., \& Sequeira, J.M. (2007). Prior family business exposure as intergenerational influence and entrepreneurial intent: 
A theory of planned behavior approach. Journal of Business Research, 60(10), 1090-1098.

Ceresia, F. \& Mendola, C. (2019). Entrepreneurial Self-Identity, Perceived Corruption, Exogenous and Endogenous Obstacles as Antecedents of Entrepreneurial Intention in Italy. Social Sciences, 8(2), 54. https://doi.org/10.3390/socsci8020054

Chikha, I.B., \& Jarboui, A. (2017). Impact of incubators on social entrepreneurship intention: an empirical study related to Tunisia. International Journal of Social Entrepreneurship and Innovation, 4(4), 305-323.

Cho, M.H. (1998). Ownership structure, investment, and the corporate value: an empirical analysis. Journal of Financial Economics, 47(1), 103-121.

Cronbach, L.J. (1951). Coefficient alpha and the internal structure of tests. Psychometrika, 16(3), 297-334.

Durbin, J., \& Watson, G.S. (1951). Testing for serial correlation in least squares regression. II. Biometrika, 38(1/2), 159-177.

Elali, W., \& Al-Yacoub, B. (2016). Factors affecting entrepreneurial intentions among Kuwaitis. World Journal of Entrepreneurship, Management and Sustainable Development, 12(1), 18-34.

Forster, F., \& Grichnik, D. (2013). Social entrepreneurial intention formation of corporate volunteers. Journal of Social Entrepreneurship, 4(2), 153-181.

Fowler, A. (2013). The virtuous spiral: A guide to sustainability for NGOs in international development. Abingdon, UK: Routledge.

Giles, M., Mcclenahan, C., Cairns, E., \& Mallet, J. (2004). An application of the theory of planned behaviour to blood donation: the importance of self-efficacy. Health Education Research, 19(4), 380-391.

Hair, J.F., Black, W.C., Babin, B.J., \& Anderson, R.E. (2010). Multivariate data analysis. Hoboken, NJ: Pearson.

Hockerts, K. (2015). The social entrepreneurial antecedents scale (SEAS): a validation study. Social Enterprise Journal, 11(3), 260-280.

Hockerts, K. (2017). Determinants of social entrepreneurial intentions. Entrepreneurship Theory and Practice, 41(1), 105130 .

Ip, C.Y., Wu, S.C., Liu, H.C., \& Liang, C. (2017). Revisiting the antecedents of social entrepreneurial intentions in Hong Kong. International Journal of Educational Psychology, 6(3), 301-323.

Kautonen, T., Luoto, S. \& Tornikoski, E.T. (2010). Influence of work history on entrepreneurial intentions in 'prime age' and 'third age': A preliminary study. International small business journal, 28(6), 583-601.

Kim, J.-E. (2019). The impact of creative role identity and creative self-efficacy on employee creativity in the hotel business. Journal of Asian Finance, Economics and Business, 6(2), 123133. https://doi.org/10.13106/jafeb.2019.vol6.no2.123

Krueger, N. (1993). The impact of prior entrepreneurial exposure on perceptions of new venture feasibility and desirability. Entrepreneurship Theory and Practice, 18(1), $5-21$.
Krueger, N.F., \& Carsrud, A.L., (1993). Entrepreneurial intentions: applying the theory of planned behaviour. Entrepreneurship \& Regional Development, 5(4), 315-330.

Lacap, J.P.G., Mulyaningsih, H.D., \& Ramadani, V. (2018). The mediating effects of social entrepreneurial antecedents on the relationship between prior experience and social entrepreneurial intent: The case of Filipino and Indonesian university students. Journal of Science and Technology Policy Management, 9(3), 329-346.

Liñán, F., \& Fayolle, A. (2015). A systematic literature review on entrepreneurial intentions: citation, thematic analyses, and research agenda. International Entrepreneurship and Management Journal, 11(4), 907-933.

Liang, C., Chang, C.C., Liang, C.T., \& Liu, Y.C. (2017). Imagining future success: Imaginative capacity on the perceived performance of potential agrisocio entrepreneurs. Thinking Skills and Creativity, 23, 161-174.

Lu, H., \& Wang, J. (2018). Entrepreneurial intention of two patterns of planned behaviour and alertness: empirical evidence in China. Journal of Asian Finance Economics and Business, 5(2), 63-72. https://doi.org/10.13106/jafeb.2018.vol5.no2.63

Luc, P. T. (2018). The relationship between perceived access to finance and social entrepreneurship intentions among university students in Vietnam. Journal of Asian Finance, Economics and Business, 5(1), 63-72. http://dx.doi.org/10.13106/jafeb.2018. vol5.no1.63

Mair, J., \& Noboa, E. (2006). Social entrepreneurship: How intentions to create a social venture are formed. In Social entrepreneurship (121-135). Palgrave Macmillan, London.

Mair, J., Robinson, J., \& Hockerts, K. (2006). Social entrepreneurship. New York, NY: Palgrave Macmillan.

Kadir, M.B.A., Salim, M., \& Kamarudin, H. (2012). The relationship between educational support and entrepreneurial intentions in Malaysian higher learning institution. ProcediaSocial and Behavioral Sciences, 69, 2164-2173.

Nowak, A. (2012). Social Entrepreneurship: Theory and Practice. New York, NY: Cambridge University Press.

Peterman, N.E., \& Kennedy, J. (2003). Enterprise education: Influencing students' perceptions of entrepreneurship. Entrepreneurship Theory and Practice, 28(2), 129-144.

Rashid, A.T. (2010). Development through social entrepreneurship: Perspectives and evidence from Bangladesh. Canadian Journal of Development Studies/Revue Canadienne D'études Du Développement, 30(3-4), 441-455.

Sánchez, J.C. (2011). University training for entrepreneurial competencies: Its impact on intention of venture creation. International Entrepreneurship and Management Journal, 7(2), 239-254.

Shaw, E., \& Carter, S. (2007). Social entrepreneurship: Theoretical antecedents and empirical analysis of entrepreneurial processes and outcomes. Journal of Small Business and Enterprise Development, 14(3), 418-434. 
Souitaris, V., Zerbinati, S., \& Al-Laham, A. (2007). Do entrepreneurship programmes raise entrepreneurial intention of science and engineering students? The effect of learning, inspiration and resources. Journal of Business Venturing, 22(4), 566-591.

Thompson, E.R. (2009). Individual entrepreneurial intent: Construct clarification and development of an internationally reliable metric. Entrepreneurship Theory and Practice, 33(3), 669-694.

Tiwari, P., Bhat, A.K., \& Tikoria, J. (2017a). The role of emotional intelligence and self-efficacy on social entrepreneurial attitudes and social entrepreneurial intentions. Journal of Social Entrepreneurship, 8(2), 165-185.

Tiwari, P., Bhat, A.K., \& Tikoria, J. (2018b). Factors Affecting Individual's Intention to Become a Social Entrepreneur. In: Social Entrepreneurship and Sustainable Business Models (59-98). Cham, Switzerland: Palgrave Macmillan.

Tiwari, P., Bhat, A.K., \& Tikoria, J. (2017c). An empirical analysis of the factors affecting social entrepreneurial intentions. Journal of Global Entrepreneurship Research, 7(1), p.1-25.

Tran, A.T., \& Von Korflesch, H. (2016). A conceptual model of social entrepreneurial intention based on the social cognitive career theory. Asia Pacific Journal of Innovation and Entrepreneurship, 10(1), 17-38.

Turker, D., \& Sonmez Selçuk, S. (2009). Which factors affect entrepreneurial intention of university students? Journal of European Industrial Training, 33(2), 142-159.
Vodă, A.I., \& Florea, N. (2019). Impact of Personality Traits and Entrepreneurship Education on Entrepreneurial Intentions of Business and Engineering Students. Sustainability, 11(4), 1192. https://doi.org/10.3390/su11041192

Vining, J., \& Ebreo, A. (1989). An evaluation of the public response to a community recycling education program. Society \& Natural Resources, 2(1), 23-36.

Wu, S., \& Wu, L. (2008). The impact of higher education on entrepreneurial intentions of university students in China. Journal of Small Business and Enterprise Development, 15(4), 752-774.

Yiu, D.W., Wan, W.P., Ng, F.W., Chen, X., \& Su, J. (2014). Sentimental drivers of social entrepreneurship: A study of China's Guangcai (Glorious) Program. Management and Organization Review, 10(1), 55-80.

Yurtkoru, E.S., Kuşcu, Z.K., \& Doğanay, A. (2014). Exploring the antecedents of entrepreneurial intention on Turkish university students. Procedia-Social and Behavioral Sciences, 150, 841850.

Zeyen, A., Beckmann, M., Mueller, S., Dees, J.G., Khanin, D., Krueger, N., Murphy, P.J., Santos, F., Scarlata, M., Walske, J., \& Zacharakis, A. (2013). Social entrepreneurship and broader theories: Shedding new light on the 'Bigger Picture'. Journal of Social Entrepreneurship, 4(1), 88-107.

Zhang, Y., Duysters, G., \& Cloodt, M. (2014). The role of entrepreneurship education as a predictor of university students' entrepreneurial intention. International Entrepreneurship and Management Journal, 10(3), 623-641. 